\title{
Integration of Traditional and E-Learning Methods to Improve Learning Outcomes for Dental Students in Histopathology
}

\begin{abstract}
Armin Ariana; Moein Amin; Sahar Pakneshan; Elliot Dolan-Evans; Alfred K. Lam
Abstract: Dental students require a basic ability to explain and apply general principles of pathology to systemic, dental, and oral pathology. Although there have been recent advances in electronic and online resources, the academic effectiveness of using self-directed e-learning tools in pathology courses for dental students is unclear. The aim of this study was to determine if blended learning combining e-learning with traditional learning methods of lectures and tutorials would improve students' scores and satisfaction over those who experienced traditional learning alone. Two consecutive cohorts of Bachelor of Dentistry and Oral Health students taking the general pathology course at Griffith University in Australia were compared. The control cohort experienced traditional methods only, while members of the study cohort were also offered self directed learning materials including online resources and online microscopy classes. Final assessments for the course were used to compare the differences in effectiveness of the intervention, and students' satisfaction with the teaching format was evaluated using questionnaires. On the final course assessments, students in the study cohort had significantly higher scores than students in the control cohort $(\mathrm{p}<0.01)$. Analysis of questionnaire results showed improved student satisfaction with the course in the study cohort. These findings suggest that the use of e-learning tools such as virtual microscopy and interactive online resources for delivering pathology instruction can be an effective supplement for developing dental students' competence, confidence, and satisfaction.
\end{abstract}

Dr. Ariana is at the School of Medicine, Griffith University, Queensland, Australia; Mr. Amin is at the School of Medicine, Griffith University, Queensland, Australia; Dr. Pakneshan is at the School of Medicine, Griffith University, Queensland, Australia; Dr. Dolan-Evans is at the School of Medicine, Griffith University, Queensland, Australia; and Dr. Lam is Professor, School of Medicine, Griffith University, Queensland, Australia. Direct correspondence to Dr. Armin Ariana, Griffith University School of Medicine, G40_6.55 Parkland Drive, Southport, Gold Coast, Queensland 4222, Australia; +61756780373; a.ariana@griffith.edu.au.

Keywords: dental education, basic sciences, pathology, histology, e-learning, blended learning, virtual microscopy

Submitted for publication 12/14/15; accepted 2/2/16

$\mathrm{D}$ ental health professionals have an important role in the improvement of public health, so it is imperative to recognize the importance of maximizing their learning capacity and knowledge acquisition. ${ }^{1}$ Pathology, defined as the study of disease, is one of the most significant subjects in oral health studies. ${ }^{2}$ Knowledge of the processes associated with disease is an essential part of the practice of dentistry, and dentists must be aware of the impact of disease on the normal function of human body. ${ }^{3}$ Dental students require a basic ability to explain and apply the general principles of pathology to systemic, dental, and oral pathology. There have been considerable challenges among dental schools to tailor their curricula to remain relevant and engaging to dental students. ${ }^{4}$

With recent advances in technology and access to electronic material, our educational methods must evolve to meet the demands of students and society. ${ }^{5}$ To fulfill dental schools' obligations to their students and the profession, they must attempt to integrate teaching, learning, and technology. ${ }^{6}$ Blended learning, which combines e-learning with traditional face-to-face teaching methods, has been found to improve learning outcomes in such areas as cephalometry, ${ }^{7}$ prosthetic dentistry, ${ }^{8}$ and radiology. ${ }^{9}$ However, the effectiveness of blended learning has not yet been studied in teaching a pathology course to dental students.

The light microscope has long been used in dental education, particularly in the areas of histology and pathology. ${ }^{10}$ However, the quality and consistency of light microscopes are often criticized, and their use by students has been described as difficult, frustrating, and tiresome; so their engagement in the course may not be ideal." There is an increas- 
ing tendency at medical schools to digitize whole microscope histopathological slides from teaching collections for web-based studies. ${ }^{12}$ Digital microscopy is a technology that utilizes the computer to scan and view a slide specimen. Following slide preparation in the usual way, slides are digitally scanned at a high resolution, which then makes the specimen amenable to analysis and interpretation via viewing on a computer. This offers a more flexible, accurate, and engaging approach in providing content to students. ${ }^{13}$ Furthermore, as an increasing number of dental schools are providing some form of e-learning, use of digital microscopy along with self-directed online teaching may be more beneficial for students. ${ }^{14}$ Possible advantages of online teaching could be avoiding traveling to attend lectures and allowing students to progress through the course at their own pace according to their own level of expertise and confidence. ${ }^{15,16}$

The aim of our study was to assess the effectiveness of adding an electronic self-directed learning tool to traditional teaching methods by measuring students' performance, understanding, and satisfaction in a general pathology course. This information could be used to modify the curriculum to increase the level of student knowledge and satisfaction.

\section{Materials and Methods}

Griffith University granted full ethical approval for the study and the use of students' results and responses (MED/05/12/HREC). All students in two consecutive cohorts of second-year dental students at Griffith University participated in the pathology course. Students in the control cohort $(\mathrm{N}=90)$ received traditional lectures followed by practical microscopy laboratory. Students in the subsequent cohort (study cohort, $\mathrm{N}=104$ ) were also given access to electronic self-directed learning material. All students were asked to complete a questionnaire at the end of their course. They were informed about the study and were given information sheets and a consent form. Those who did not wish to complete the questionnaire could submit a blank form to avoid being identified or disadvantaged as a result of not participating. To avoid bias, names and student numbers were not recorded in the questionnaires. The questionnaires were collected by a research assistant who was not a member of the academic staff of the School of Medicine.
The electronic self-directed learning tool consisted of online practical and lecture notes on topics covered in the general pathology course. The tool included a link to the Blackboard online learning management system for online Griffith University embedded websites with images of slides scanned by ScanScope Aperio CS2 (Leica Biosystems, Chicago, IL, USA). Slides showed the normal histology of the main organs, general principles of pathology such as acute and chronic inflammation, healing and repair, injury and adaptation, and neoplasia. In addition, slides from tissues with systemic pathologies referring to main topics of endocrine system, gastrointestinal and liver, respiratory, and cardiovascular systems were provided (Figure 1).

Each topic also included an interactive microscopy section to help students review the topics covered in the practical sessions (Figure 2). This tool allowed students to self-evaluate their learning by "hide and reveal tabs" for identification of criteria on each slide in addition to a diagnosis or self-assessment quiz at the end of each topic. The online learning tool was made accessible to the study cohort students on their personal computers and was compatible with hand-held devices such as mobile phones and tablets. Students and teaching staff were also able to communicate with each other via the online tool to address any questions and concerns.

The final assessment for the course consisted of five stations through which students rotated every five minutes. Each station contained a microscope, a slide from a covered pathology topic, and five shortanswer questions for each case referring to cellular structures, morphology, diagnosis, and pathological insight. The short-answer questions included appropriate space to answer each. Each question was designed so that there was only one correct answer for each, and it was not in a descriptive format that demanded the examiner's descriptive judgment. Although the faculty graders were aware that one of the cohorts had access to online material in addition to the traditional resources, they were not aware of the research at the time of grading, nor was there any chance of discriminative grading due to the design of the short-answer questions. The effectiveness of the intervention in achieving the desired learning outcomes was examined by summative final assessment in both cohorts.

To measure students' level of satisfaction with the education methods used, a questionnaire was designed to cover both lecture series and practical 


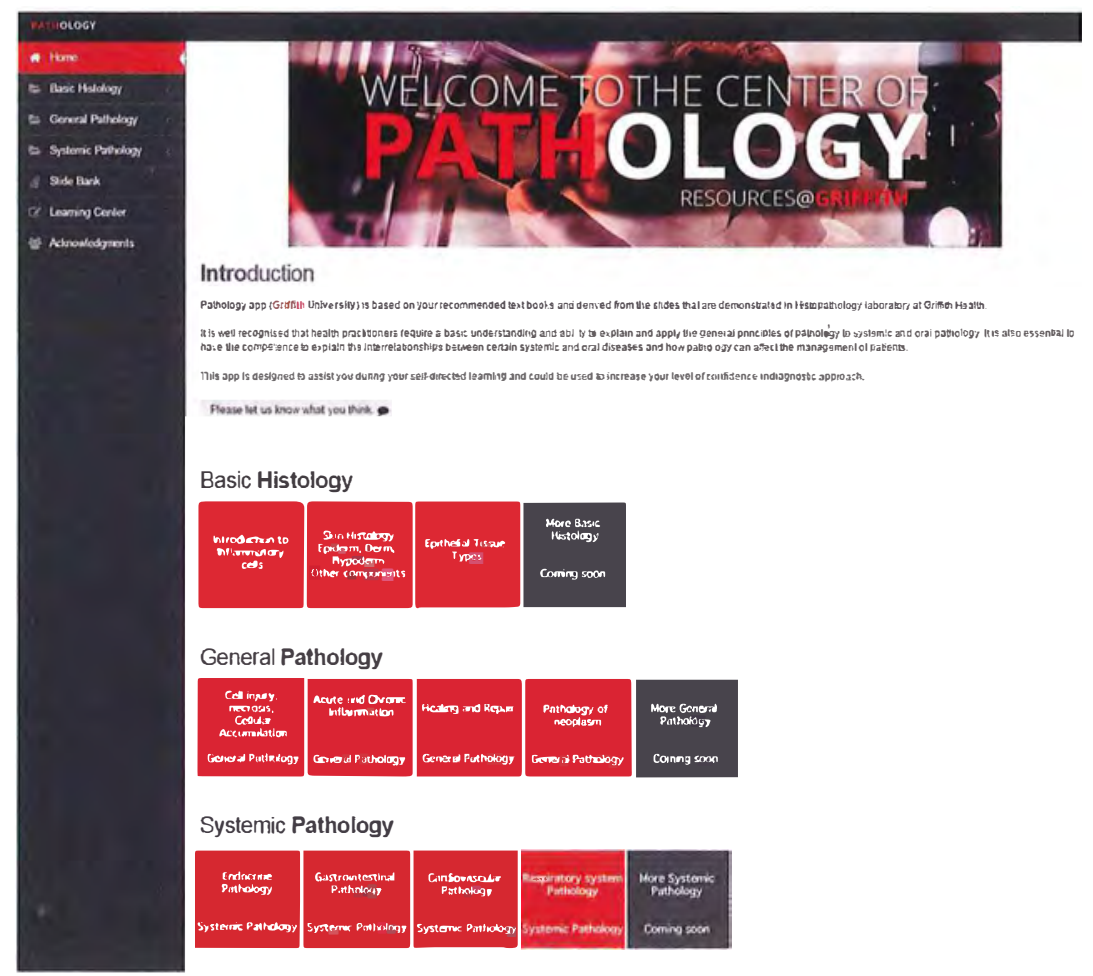

Figure 1. Front page of pathology application, the main entry to online blended learning tool

Note: Homepage with user friendly features guide students to select a topic and review slides addressing general and basic histology of main organs, general principles of pathology such as acute and chronic inflammation, healing and repair, injury and adaptation, and neoplasia or look into tissues with different systemic pathologies in endocrine system, gastrointestinal and liver, respiratory, and and neoplasia or look into tissues with different systemic pathologies in endocrine system, gastrointestinal and liver, respiratory, and
cardiovascular systems. Slide banks show all the slides in the package in one page for quick access. Learning center was designed for self-assessment items such as quizzes and sample questions.

workshops. The questionnaire consisted of two sets of statements with response options on a five- or seven-point rating scale, as well as a free text opportunity to provide comments on the perceived educational value of the pathology course.

End of semester exams were graded twice by two lecturers on the subject, and grades were reported out of $100 \%$ for fully correct answers. The collected data (exam grades) and responses on the questionnaire were analyzed using Statistical Package for Social Sciences, Version 22.0 (IBM Corp., New York, NY, USA). Independent-samples t-test was used to test for differences between the final exam results for the two groups. The results were presented as mean values \pm standard error of the mean (SEM). Pearson's chi-square test was used to test for differences between the survey responses in each group. The significance threshold was set at $\mathrm{p} \leq 0.05$. Prism 3 (GraphPad Software, La Jolla, CA, USA) was used to show the graph. Equal variances were not assumed since the variability between the results in each group was significant.

\section{Results}

The course convener reported full participation of both cohorts (control cohort $\mathrm{N}=90$, study cohort $\mathrm{N}=104$ ) in practical laboratory sessions and weekly lectures in both years. Blinded records of students' online activities showed that all students in the study cohort used the online learning tool $(\mathrm{N}=104,100 \%)$. The online statistical report showed that the online resources received 3,473 hits during the study semester, with the highest hits on Fridays when the practical sessions were delivered (29.23\%) followed by Wednesdays when lecture materials were presented $(21.74 \%)$. Saturday and Sundays had the lowest number of hits. The report showed that most of the online interaction started about 9:00 in the 

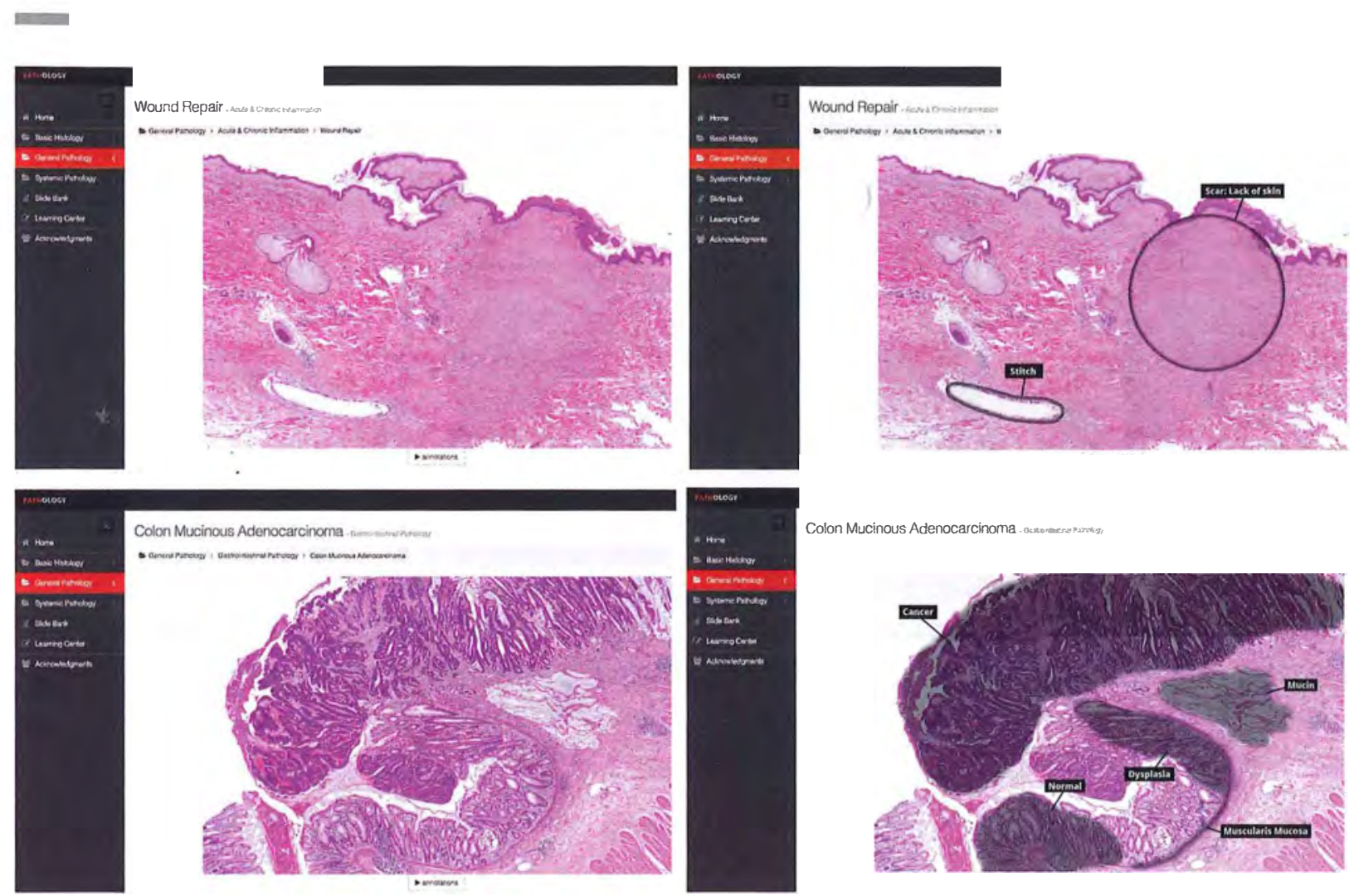

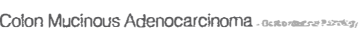

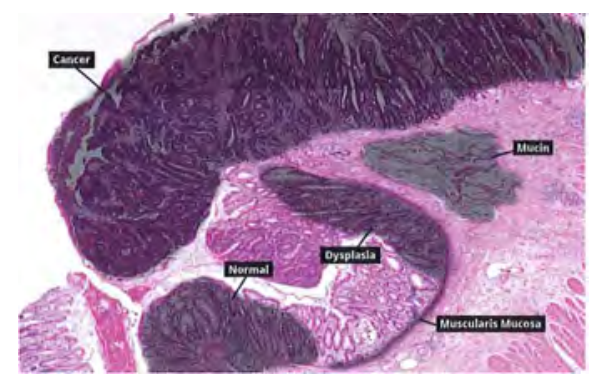

Figure 2. Examples of interactive online microscopy facility

Note: Images on left column are 20X zoom of two tissues: skin with repair process (top) and colon adenocarcinoma (bottom). Same images after click of annotation tab on 20X revealed a description of histopathological features of slides.

morning ( $10 \%$ of all hits), spiking till noon $(12.6 \%$ of all hits), and slowly decreasing to $3 \%$ of all hits by midnight. This report provided useful information about the educational habits and behavior of our students online (Figure 3 ).

Figure 4 shows the mean final exam grades for the study and control cohorts. There was a significant difference between the grades of the study cohort $(96.13 \% \pm 5.73 \%)$ and the control cohort $(85.43 \% \pm 10.23 \%)$. Analysis of students' academic performance in other dental courses revealed insignificant differences between the two cohorts. We also assessed the selection criteria for admission to the dental program for these two cohorts, and their grade point averages (GPAs) were similar, indicating homogeneity in academic performance of these two cohorts.

On the questionnaire indicating students' perceptions of the course, respondents were 90 students in the control group (100\% response rate) and 86 students in the study group ( $83 \%$ response rate).
Students were asked the extent to which they agreed with a series of statements. Questions 1-7 used a five-point Likert scale (from 1=strongly disagree to $5=$ strongly agree), and question 8 used a seven-point rating scale (from $1=$ poor to $7=$ excellent).

Mean scores on all statements indicated a high level of satisfaction with the general pathology course (Table 1). There was no significant difference in responses between the cohorts on statements $1,4,7$, and 8 regarding organization of the course, effectiveness of lecture delivery, satisfaction with the quality of the components, and the course's effectiveness in their learning. Statistically significant differences in responses were found on statements 2, 3, and 6 on which students were asked about the feedback process, their engagement in learning, and the fairness of the assessment. In response to statement 4 ("The teaching [lecturers and demonstrators] on this component was effective in helping me to learn"), students in both cohorts found the traditional learning methods useful (mean scores of 4.73 and 4.71). 


\section{Content Usage Statistics}

\section{Access / Date}
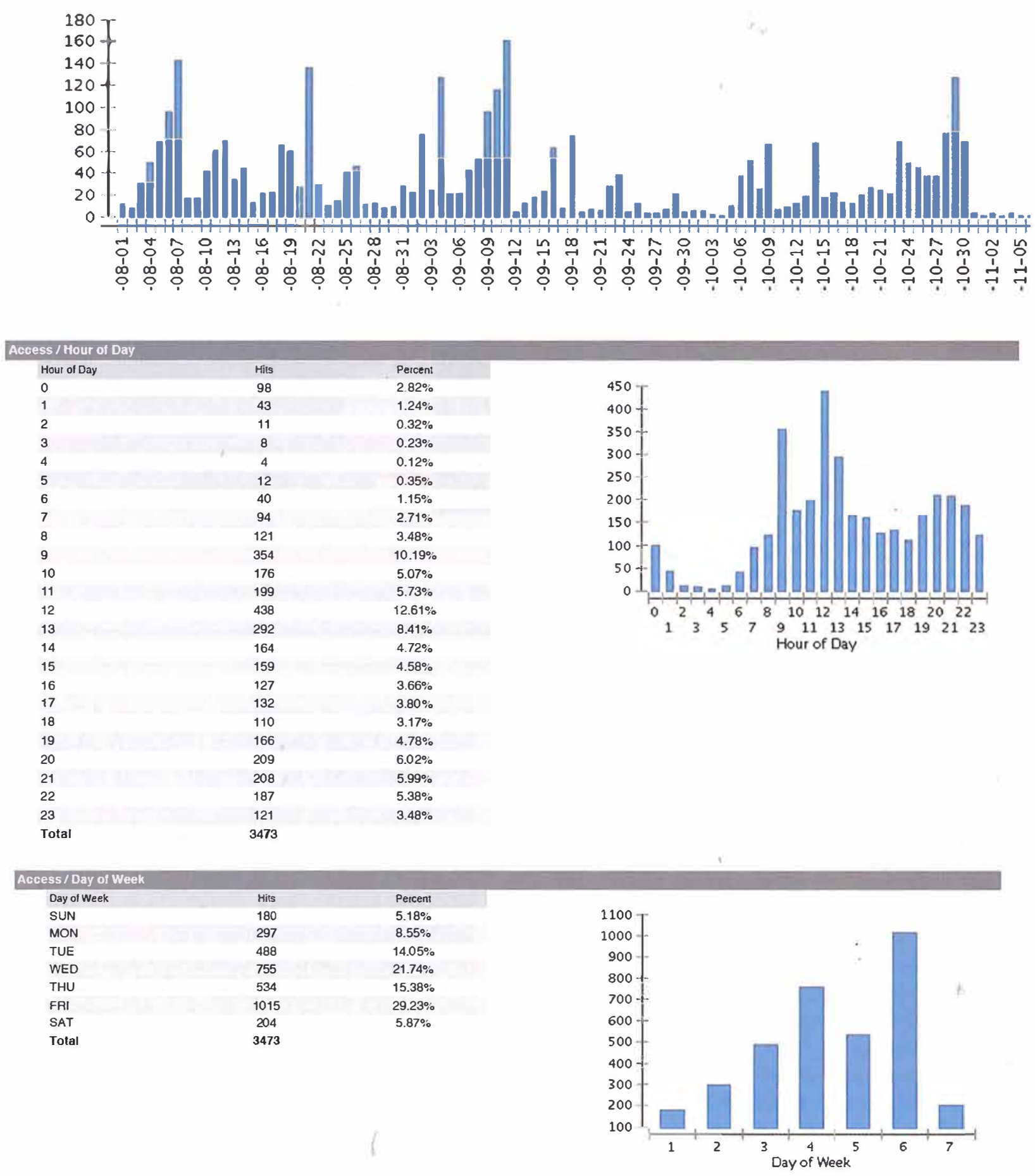

Figure 3. Online content usage statistics 


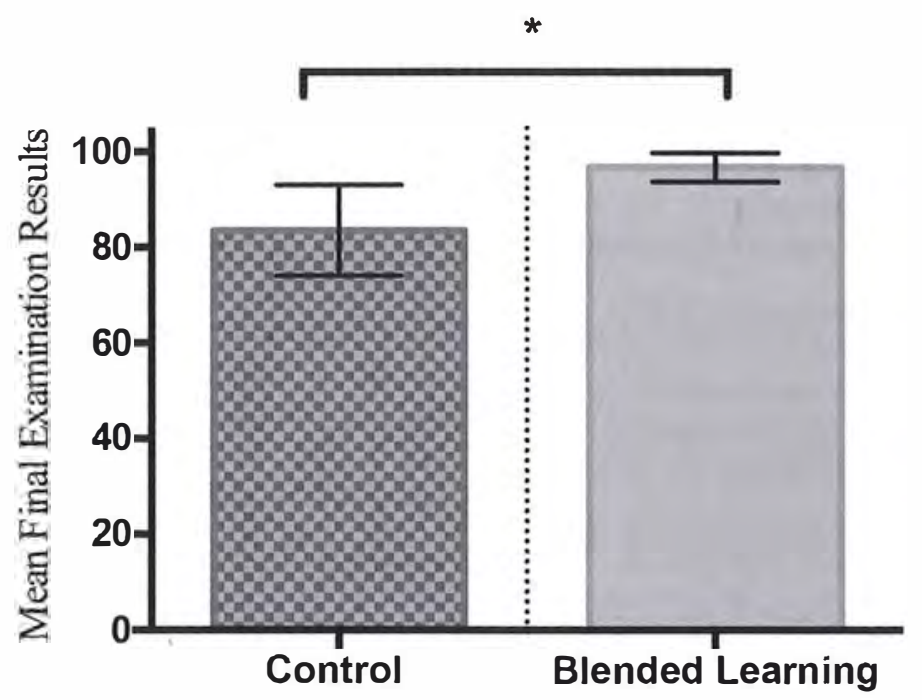

Figure 4. Mean final examination results for general pathology course in control and study cohorts (blended learning)

Note: Standard deviations for control and study cohorts were 2.85 and 1.67 , respectively.

*Statistically significant difference between cohorts

There was no significant difference in response to that question between the cohorts. In response to statement 5 ("Learning material would be more effective in helping me to learn the general pathology if available online"), students in the control cohort reported that online resources would be useful in their learning (mean score of 4.81).

\section{Discussion}

Self-directed learning is the process whereby an individual takes the initiative in determining his or her learning needs and setting his or her own learning goals, putting an appropriate plan into practice, and evaluating the learning outcome. ${ }^{17} \mathrm{Advances}$ in technology and software, together with a heightened appreciation of self-directed learning, have fostered interest among busy instructors in the development of computer-based multimedia instruction programs, which are interactive, self-paced, self-directed, and, unlike some instructors, never distracted, too tired, or in too much of a hurry. Self-directed learning programs are easily accessible for individual students or small groups. The instructor may work with students in a lecture hall setting or in a problem-based learning setting. ${ }^{18}$
Health professions education has many examples of online learning, in both the basic sciences and clinical teaching. As students are usually in large groups for basic science teaching, web-based learning can be used to provide learning materials to complement conventional methodologies and enable self-assessment-for example, access to anatomical sites and image banks for pathology courses. Online learning can be useful to support clinical teaching when learners are geographically dispersed, such as learning clinical skills through video demonstrations. ${ }^{19}$

The integration of face-to-face learning experiences with online experiences is called blended learning. ${ }^{20,21}$ Whilst two studies found no significant advantage in self-directed learning compared to traditional learning methods, ${ }^{22,23}$ another study affirmed the advantages of blended learning models in health sciences. ${ }^{24}$ Schmidt et al. introduced a blended learning model instead of an exclusive instructor-led approach to teach microscopic anatomy. ${ }^{25}$ They used virtual microscopy and developed what they called an intelligent virtual microscope, MyMiCROscope. The results of their evaluation showed a very high acceptance of MyMiCROscope by the students (medical, dental, and molecular medicine). They found that $90 \%$ of the students affirmed MyMiCROscope 
Table 1. Students' perceptions of the general pathology course, by control and study groups

\begin{tabular}{|c|c|c|c|c|c|}
\hline \multirow[b]{2}{*}{ Question } & \multicolumn{2}{|c|}{ Number } & \multicolumn{2}{|c|}{ Mean } & \multirow[b]{2}{*}{ p-value } \\
\hline & Control & Study & Control & Study & \\
\hline 1. This component was well organized. & 90 & 86 & 4.63 & 4.58 & NS \\
\hline 2. I received helpful feedback and support. & 89 & 86 & 4.61 & 4.81 & 0.002 \\
\hline 3. This component engaged me in learning. & 90 & 86 & 4.42 & 4.67 & 0.034 \\
\hline $\begin{array}{l}\text { 4. The teaching (lecturers and demonstrators) on this component was } \\
\text { effective in helping me to learn. }\end{array}$ & 89 & 86 & 4.73 & 4.71 & NS \\
\hline $\begin{array}{l}\text { 5. Learning material would be more effective in helping me to learn } \\
\text { general pathology if available online. }{ }^{\dagger}\end{array}$ & 90 & & 4.81 & & \\
\hline 6. The pathology practical's assessment was clear and fair. & 90 & 86 & 4.56 & 4.86 & 0.003 \\
\hline 7. Overall, I am satisfied with the quality of this component. & 90 & 86 & 4.67 & 4.76 & NS \\
\hline 8. Overall, how effective was this component in helping you to learn? & 89 & 85 & 6.40 & 6.33 & NS \\
\hline
\end{tabular}

NS=no significant difference between groups.

tThis question was asked only of the control group.

Note: Questions 1-7 used a five-point Likert scale (from $1=$ strongly disagree to $5=$ strongly agree), and question 8 used a seven-point rating scale (from $1=$ poor to $7=$ excellent).

motivated them to learn and enhanced their sense of achievements, and $97 \%$ reported feeling confident that MyMiCROscope supported their consolidation of knowledge and improved their performance in microscopic anatomy. With the implementation of MyMiCROscope, the learning behavior of their students changed towards group work and social interactions.

Pathology is a very visual subject, and the possibilities of using information technology to enhance learning are widely appreciated..$^{26} \mathrm{~A}$ recent study found that students were almost always satisfied and in favor of using information technology when they were entering into learning the field of pathology. ${ }^{27}$ Addition of e-learning materials to traditional teaching methods such as lectures and handouts creates a blended model of learning that may be highly advantageous. ${ }^{28}$ The many advantages of using blended learning in pathology include increase in accessibility and availability, ease of publishing web documents, search capability, and opportunity for collaboration. ${ }^{29}$

Effectiveness of a teaching model can be evaluated using objective parameters such as academic results as well as subjective parameters such as student satisfaction. We used both forms of evaluation in our study, based on others' experience with measuring the effectiveness of blended learning compared with traditional methods in teaching pathology to dental students. ${ }^{9,30,31}$ In our study, compared to the control cohort who experienced only traditional methods, the study cohort (which also had access to self-directed online learning) performed significantly better in final assessment $(85.43 \%$ versus $96.13 \%$ on final exams). Similar improvements have been reported in previous studies related to teaching radiology and prosthodontics courses to dental students. .,32 $^{9}$ However, other studies have found no significant increase in academic results after introduction of blended learning. ${ }^{33-35}$

To understand the factors contributing to improved student performance in the blended learning in our study, student responses to the questionnaire were analyzed. In response to question 2 ("I received helpful feedback and support"), students in the study cohort had significantly higher scores than students in the control group. The online self-directed learning tool allowed students and the teaching staff to interact blindly with each other to resolve students' concerns and questions relating to the teaching material. These students were also able to self-evaluate their knowledge and receive feedback by completing quizzes at the end of each topic. In this way, students can receive continuous timely feedback and supportive strategies to improve their learning, in the same way as reported in studies by $\mathrm{Goh}^{36}$ and Marei and Al-Khalifa. ${ }^{37}$

With regards to question 3 ("This component engaged me in learning"), students in the control group reported finding the course more engaging than students in previous years. The online learning tool was designed to be interactive to maximize students' engagement and learning. Gogolin and Swartz found that students' engagement and self-confidence in a subject were crucial to success in that subject, ${ }^{38}$ and Diaz-Granados et al. reported that students' attitudes and learning styles had a substantial impact on their achievements. ${ }^{39}$ Therefore, it is crucial to maximize students' engagement level and provide 
as many learning tools as possible to increase their success rate.

In our study, in response to statement 5 ("Learning material would be more effective in helping me to learn the general pathology if available online"), the mean response from the control group was very high (4.81). This response suggests that, before introduction of online self-directed learning, students wanted a more flexible and accessible learning tool. This finding was similar to that in other studies that reported students anticipated an improvement in their performance by implementation of self-directed electronic learning. ${ }^{31,40,41}$

Also in our study, the study cohort's responses to statement 6 ("The pathology practical's assessment was clear and fair") were significantly higher than responses in the study cohort. This finding suggests that use of online material increased students' perception that the final exam in the course was fair. Perhaps students found it more convenient to examine materials such as images of the slides when it was online rather than those who had to attend the lab and look into the microscope. The online self-evaluation quizzes at the end of each topic may also have helped students focus their learning and adjust their study patterns. The online tool allowed students with slower learning capabilities to review the material in their own time. These results are in agreement with similar studies that found use of blended learning models improved students' preparation for the course by adding extra flexibility, availability, and self-evaluation. ${ }^{8,42}$

Our findings were consistent with previous research that found use of web-based learning resulted in higherstudent satisfaction and engagement. ${ }^{43-45} \mathrm{Al}$ though online learning is an attractive option to most students, Cook et al. found that web-based learning had not been proven to increase learning efficiency and end results. ${ }^{43}$ This could be due to differences in learning styles, degree of familiarity with technology, and quality of online interface. Therefore, the limitations of web-based learning must also be acknowledged. One of its major problems, especially with data-dense content such as histopathology images in a pathology course, is download time, although that can be addressed by development of a CD-ROM that obviates the need for Internet access. ${ }^{46}$

\section{Conclusion}

This study found that students who experienced integrated online learning modules along with tra- ditional teaching methods performed better in the general pathology course and found the course more helpful and engaging than those who experienced only the traditional methods. This difference may have been due to the better accessibility, access to self-evaluation, higher student engagement, and the ease of receiving support from the teaching staff that were made available in the online learning modules.

\section{Acknowledgments}

The authors would like to acknowledge Prof. Ken Donald for his constructive review and fruitful comments on this paper. We also would like to thank two special staff members at Griffith University School of Medicine: Ms. Melissa Leung for preparation of Scanscope images, and Mr. Jacob Sharples for brilliant online design and constant support.

\section{Disclosure}

The authors reported no conflicts of interest or disclosures.

\section{REFERENCES}

1. Bertolami CN. Rationalizing the dental curriculum in light of current disease prevalence and patient demand for treatment: form vs. content. J Dent Educ 2001;65(8):725-35.

2. Ibsen OA, Phelan JA. Oral pathology for the dental hygienist. St. Louis: Elsevier Health Sciences, 2014.

3. DeLong L, Burkhart N. General and oral pathology for the dental hygienist. Philadelphia: Lippincott, Williams \& Wilkins, 2013.

4. Darling MR, Daley TD. Oral pathology in the dental curriculum: a guide on what to teach. J Dent Educ 2006;70(4):355-60.

5. Mattheos N, Stefanovic N, Apse P, et al. Potential of information technology in dental education. Eur J Dent Educ 2008;12(Suppl 1):85-92.

6. Ford PJ, Foxlee N, Green W. Developing information literacy with first-year oral health students. Eur J Dent Educ 2009;13(1):46-51.

7. Ludwig B, Bister D, Schott TC, et al. Assessment of two e-learning methods teaching undergraduate students cephalometry in orthodontics. Eur J Dent Educ 2015.

8. Reissmann DR, Sierwald I, Berger F, Heydecke G. A model of blended learning in a preclinical course in prosthetic dentistry. J Dent Educ 2015;79(2):157-65.

9. Kavadella A, Tsiklakis K, Vougiouklakis G, Lionarakis A. Evaluation of a blended learning course for teaching oral radiology to undergraduate dental students. Eur J Dent Educ 2012;16(1):e88-95.

10. Farah CS, Maybury TS. The e-evolution of microscopy in dental education. J Dent Educ 2009;73(8):942-9.

11. Farah CS, Maybury T. Implementing digital technology to enhance student learning of pathology. Eur J Dent Educ 2009;13(3):172-8. 
12. Dee FR. Virtual microscopy in pathology education. Hum Pathol 2009;40(8):1112-21.

13. Szymas J, Lundin M. Five years of experience teaching pathology to dental students using the WebMicroscope Diagn Pathol 2011;6(Suppl 1):S13.

14. Holt RD, Oliver M. Evaluating web-based learning modules during an MSc program in dental public health: a case study. Br Dent J 2002;193(5):283-6.

15. Chumbler NR, Cohen DM, Bhattacharyya I, et al. University of Florida College of Dentistry's "case of the month": evaluating a web-based continuing dental education course for clinical oral pathology. J Dent Educ 2007;71(2):260-8

16. Spallek H, Pilcher E, Lee JY, Schleyer T. Evaluation of web-based dental CE courses. J Dent Educ 2002;66(3):393-404.

17. Okisaka S. [Changing aspects in continuing medical education]. Nippon Ganka Gakkai Zasshi 2007;111(2):83-8. [in Japanese]

18. Hart JK. Self-directed learning program and the library: supporting instructors in development of multimedia instructional programs. Bull Med Libr Assoc 1994;82(4):434-6.

19. McKimm J. ABC of learning and teaching: web-based learning. BMJ 2003;326(7394):870-3.

20. Garrison DR, Kanuka H. Blended learning: uncovering its transformative potential in higher education. Internet Higher Educ 2004;7(2):95-105.

21. Sinn HP, Andrulis M, Mogler C, Schirmacher P. [Virtual microscopy in pathology teaching and postgraduate training.] Pathologe 2008;29(S2):255-8. [in German]

22. De Lorenzo RA, Abbott CA. Effectiveness of an adultlearning, self-directed model compared with traditional lecture-based teaching methods in out-of-hospital training. Acad Emerg Med 2004;11(1):33-7.

23. Rowe M, Frantz J, Bozalek V. The role of blended learning in the clinical education of health care students: a systematic review. Med Teach 2012;34(4):e216-21.

24. Abutarbush SM, Naylor JM, Parchoma G, et al. Evaluation of traditional instruction versus a self-learning computer module in teaching veterinary students how to pass a nasogastric tube in the horse. J Vet Med Educ 2006;33(3):447-54

25. Schmidt C, Reinehr M, Leucht O, et al. MyMiCROscope: intelligent virtual microscopy in a blended learning model at Ulm University. Ann Anat 2011;193(5):395-402.

26. Hamilton PW, Wang Y, McCullough SJ. Virtual microscopy and digital pathology in training and education. APMIS 2012;120(4):305-15.

27. Al-Janabi S, Huisman A, Van Diest PJ. Digital pathology: current status and future perspectives. Histopathology 2012;61(1):1-9.

28. Marshall R, Cartwright N, Mattick K. Teaching and learning pathology: a critical review of the English literature. Med Educ 2004;38(3):302-13.

29. Hamza S, Anderson P, Reddy VVB, Siegal GP. Use of the internet in pathology resident training and education. Adv Anat Pathol 2001;8(5):290-7.
30. Handal B, Groenlund C, Gerzina T. Dentistry students' perceptions of learning management systems. Eur J Dent Educ 2010;14(1):50-4

31. Neuhaus KW, Schegg R, Krastl G, et al. Integrated learning in dentistry: baseline data and first evaluation at the dental school of Basel. Eur J Dent Educ 2008;12(3):163-9.

32. Faraone K, Garrett P, Romberg E. A blended learning approach to teaching preclinical complete denture prosthodontics. Eur J Dent Educ 2013;17(1):e22-7.

33. Gray K, Tobin J. Introducing an online community into a clinical education setting: a pilot study of student and staff engagement and outcomes using blended learning. BMC Med Educ 2010;10(1):6.

34. Garland KV. E-learning vs. classroom instruction in infection control in a dental hygiene program. J Dent Educ 2010;74(6):637-43.

35. Mitov G, Dillschneider T, Abed MR, et al. Introducing and evaluating MorphoDent, a web-based learning program in dental morphology. J Dent Educ 2010;74(10):1133-9.

36. Goh PS. Using a blog as an integrated e-learning tool and platform. Med Teach 2015:1-2.

37. Marei HF, Al-Khalifa KS. Pattern of online communication in teaching a blended oral surgery course. Eur J Dent Educ 2015.

38. Gogolin L, SwartzF. A quantitative and qualitative inquiry into the attitudes toward science of nonscience college students. J Res Sci Teach 1992;29(5):487-504.

39. Díaz-Granados FSI, Dominguez E, Ricardo C, Fontalvo $H$. Effects of a centered virtual teaching environment on learning styles in the academic performance of college students. Int J Emerg Technol Learn 2009;4(0):59-63.

40. Smucny J, Epling JW. A web-based approach to teaching students about diagnostic reasoning. Fam Med 2004;36(9):622-4.

41. Sisson SD, Hughes MT, Levine D, Brancati FL. Effect of an internet-based curriculum on postgraduate education: a multicenter intervention. J Gen Intern Med 2004;19 (5 Pt 2):505-9.

42. De Leng BA, Dolmans DH, Muijtjens AM, van der Vleuten CP. Student perceptions of a virtual learning environment for a problem-based learning undergraduate medical curriculum. Med Educ 2006;40(6):568-75.

43. Cook DA, Dupras DM, Thompson WG, Pankratz VS. Web-based learning in residents' continuity clinics: a randomized, controlled trial. Acad Med 2005;80(1):90-7.

44. Kamin C, O'Sullivan P, Deterding R, Younger M. A comparison of critical thinking in groups of third-year medical students in text, video, and virtual PBL case modalities. Acad Med 2003;78(2):204-11.

45. Jao CS, Brint SU, Hier DB. Making the neurology clerkship more effective: can e-textbook facilitate learning? Neurol Res 2005;27(7):762-7.

46. KlattE. Web-based pathology practice examination usage. J Pathol Inform 2014;5(1):34 